\title{
Effect of annealing on the structure and optical properties of InGaAs/GaAs quantum dots
}

Xu, Zhangcheng; Leosson, Kristjan; Birkedal, Dan; Hvam, Jørn Märcher; Sadowski, J.; Liu, Y.; Yang, K.; Zhao, Z.; Chen, X.

Published in:

International Conference on Molecular Beam Epitaxy, 2002

Link to article, DOI:

10.1109/MBE.2002.1037915

Publication date:

2002

Document Version

Publisher's PDF, also known as Version of record

Link back to DTU Orbit

Citation (APA):

Xu, Z., Leosson, K., Birkedal, D., Hvam, J. M., Sadowski, J., Liu, Y., Yang, K., Zhao, Z., \& Chen, X. (2002).

Effect of annealing on the structure and optical properties of InGaAs/GaAs quantum dots. In International

Conference on Molecular Beam Epitaxy, 2002 (pp. 373-374). IEEE. https://doi.org/10.1109/MBE.2002.1037915

\section{General rights}

Copyright and moral rights for the publications made accessible in the public portal are retained by the authors and/or other copyright owners and it is a condition of accessing publications that users recognise and abide by the legal requirements associated with these rights.

- Users may download and print one copy of any publication from the public portal for the purpose of private study or research.

- You may not further distribute the material or use it for any profit-making activity or commercial gain

- You may freely distribute the URL identifying the publication in the public portal 


\title{
Effect of Annealing on the Structure and Optical properties of InGaAs/GaAs Quantum Dots
}

\author{
Zhangcheng Xu, Kristjan Leosson, Dan Birkedal, Jørn M. Hvam
}

Research Center COM, Technical University of Denmark, Lyngby, DK-2800, Denmark

Janusz Sadowski

Niels Bohr Institute, Copenhagen University, Copenhagen, DK-2100, Denamark

Yanmei Liu, Kuntang Yang, Zongyan Zhao

Department of Physics, Anhui University, Hefei, 230039, P.R.China

Xiaoshuang Chen

Shanghai Institute of Technical Physics, Chinese Academy of Sciences, P.R.China

Corresponding author: Mr. Zhangcheng Xu, E-mail: zxu@com.dtu.dk,

Tel: $+45-45256388$ Fax: $+45-45256581$

In this paper, we report the effect of annealing on self-assembled InGaAs/GaAs quantum dots, as investigated by means of resonant photoluminescence (PL), resonant Raman scattering, polarization dependent $\mathrm{PL}$, and high resolution $\mathrm{X}$-ray diffraction.

Two InGaAs/GaAs quantum dot samples are grown in Stranski-Kranstnov (SK) mode by solid source MBE, on (001) oriented undoped GaAs substrates. A 5-monolayer- $\mathrm{In}_{0.5} \mathrm{Ga}_{0.5} \mathrm{As}$ QD layer was embedded in the GaAs matrix. One sample was in-situ annealed at $660^{\circ} \mathrm{C}$ for 11 minutes under As overpressure.

Figure 1 shows the PL spectra excited at different energies $\left(E_{e x}\right)$ at $10 \mathrm{~K}$. At $E_{e x}=1.3883 \mathrm{eV}$ close to the edge of the density of states in the wetting layer, a resonant PL peak appears on the highenergy shoulder of the broad PL band excited non-resonantly ( $E_{e x}=1.9592 \mathrm{eV}$ ), for both the asgrown and annealed samples. Resonant Raman scattering peaks are also observed in Fig. 1, the LO phonon energy of InGaAs in the annealed sample ( $34.2 \mathrm{meV})$ is higher than in the as-grown sample (33.9 meV), which means the Indium composition in the QDs of annealed sample is lower than that of as-grown sample.

Figure 2 shows the polarization of surface-emitted PL from the as-grown and annealed samples. The PL polarization anisotropy $P$ is defined as $\left(I_{[1 \overline{1} 0]}-I_{[110]}\right) /\left(I_{[110]}+I_{[1 \overline{1} 0]}\right)$, where $I_{[110]}$ and $I_{[1 \overline{1} 0]}$ are intensities polarized along the $[110]$ and $[1 \overline{1} 0]$ directions, respectively. The value of $P$ is indication of the elongation of QDs along $[1 \overline{1} 0]$ with respect to $[110]$ due to anisotropic surface diffusion of indium. As shown in Fig.2, little change in the anisotropy $P$ can be seen for the as-grown and annealed samples.

Figure 3 shows the high-resolution X-ray diffraction (XRD) rocking curves around the GaAs (004) peak. It can be seen that the fringes in the range of -1000 to -1500 arcsecs evolve into a broad tail for the annealed sample, which means the strain relief occurs in the growth direction during annealing the QDs' sample. 

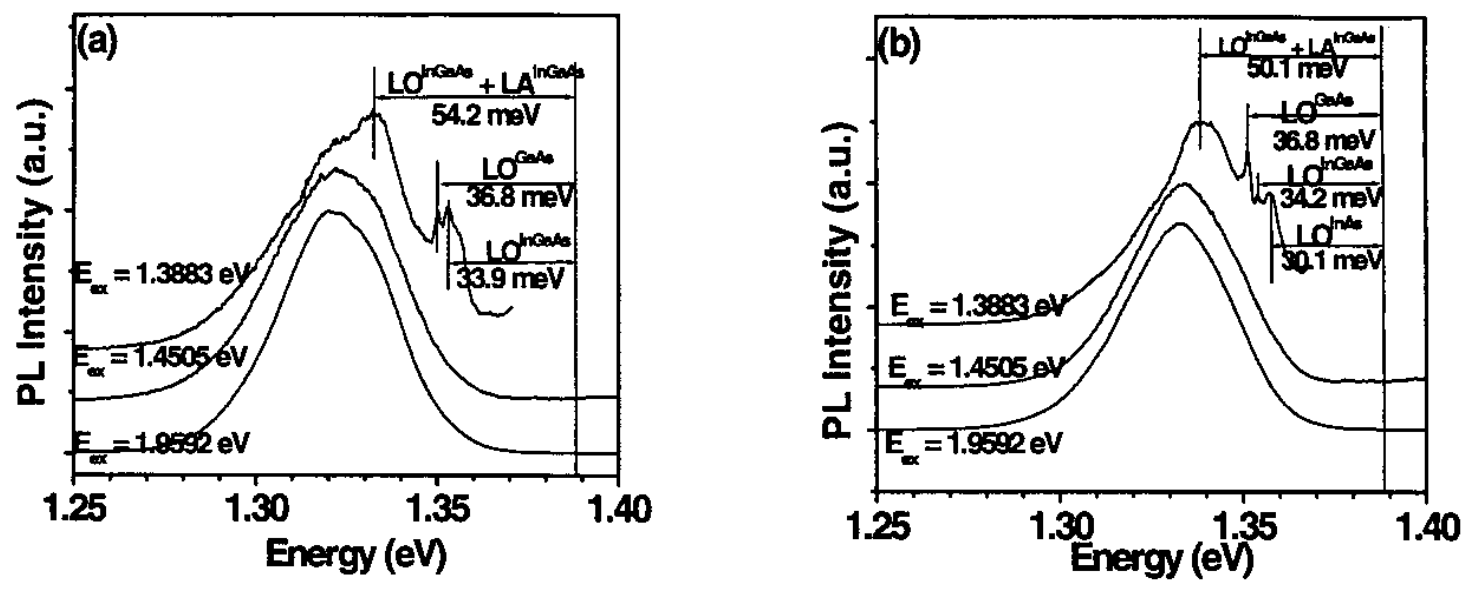

Fig. 1 PL spectra at different excitation energies at $10 \mathrm{~K}$, for (a) the as-grown sample, and (b) the annealed one

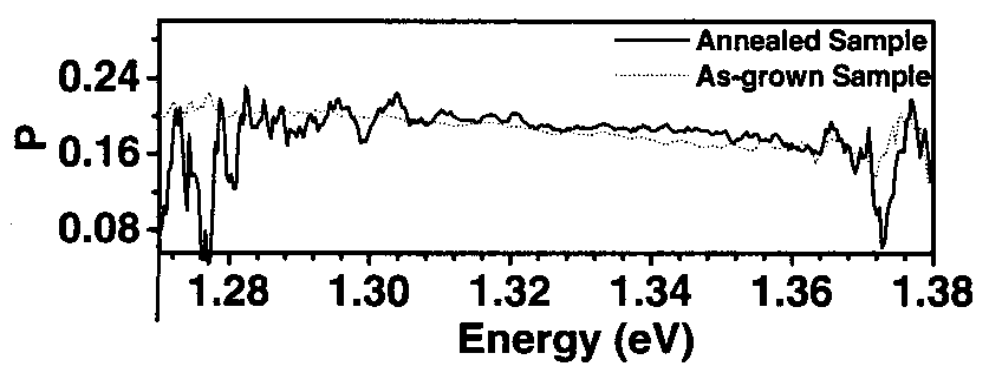

Fig. 2 PL polarization anisotropy measured at $10 \mathrm{~K}$

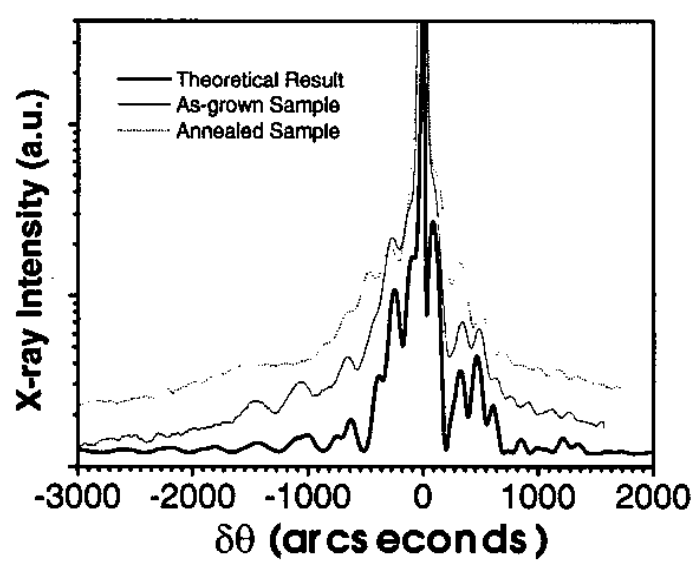

Fig. 3 High resolution XRD rocking curves around GaAs (004) peak 